
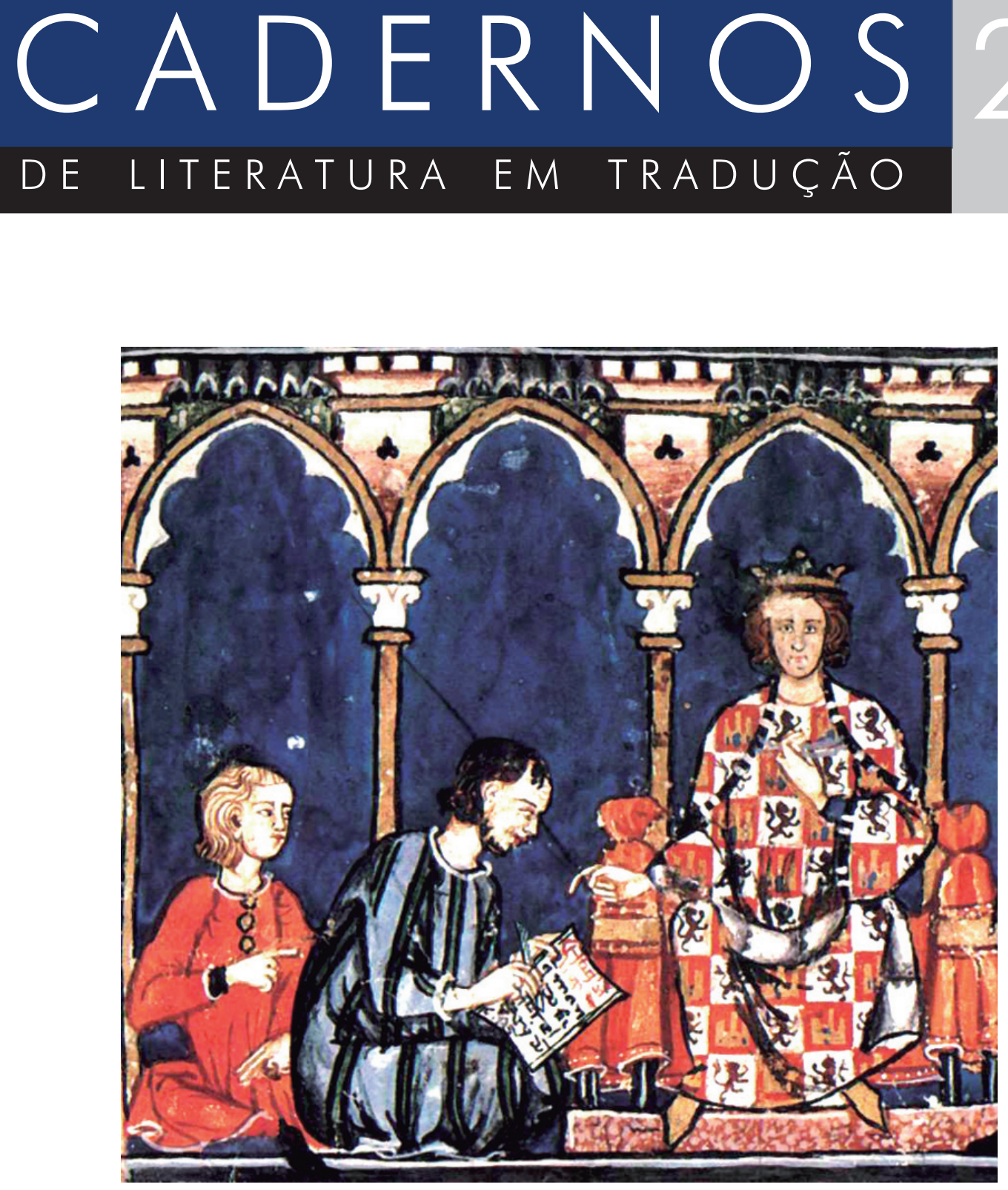

Tradutores da chamada Escola de Toledo com Afonso $X$ de Castela 


\title{
Samuel Beckett, o poeta entre as ruínas
}

\author{
Alan Cardoso da Silva ${ }^{1}$
}

Resumo: Com este trabalho apresento a minha tradução para três poemas do escritor irlandês Samuel Beckett, ainda inéditos no português do Brasil ("Dieppe", "Saint-Lô" e "Antipepsis"), os quais serão analisados como "poemas de guerra", visto que o autor os escreveu enquanto resistia ao progresso do nazismo na França. A relevância desse trabalho se dá como contribuição aos estudos acerca da poesia de Beckett (autor mais notadamente lembrado como dramaturgo e romancista do que como poeta). Esses três poemas foram escolhidos como uma proposta de rememoração de um "Beckett antifascista". A leitora e o leitor encontrarão minhas traduções ao lado dos poemas originais, seguidos de comentários que explicam as decisões tradutórias, além de fornecer interpretações para os poemas originais.

Palavras-chave: Tradução comentada. Tradução poética. Transcriação. Samuel Beckett. Beckett Antifascista.

Abstract: Within this work I present my translation for three poems by the Irish writer Samuel Beckett, still unpublished in Brazilian Portuguese, ("Dieppe", "Saint-Lô" and "Antipepsis"), which will be analyzed as "war poems", since the author wrote them while resisting to the progress of Nazism in France. The relevance of this work is given as a contribution to studies on Beckett's poetry (an author more notably remembered as a playwright and novelist than as a poet). These three poems were chosen as a proposal to commemorate an "antifascist Beckett". The readers will find my translations alongside the original poems, followed by comments that explain the translational decisions, in addition to providing interpretations for the original poems.

Keywords: Translation with commentary. Poetry translation. Transcreation. Samuel Beckett. Antifacist Beckett.

1 Graduando em Letras Português-Literaturas pela Universidade Federal Fluminense (UFF) e estudante do Núcleo de Tradução e Criação (ntc/UFF), onde desenvolveu monografia sobre a tradução de poemas antifascistas de Samuel Beckett. Seu livro de poesia Aught foi publicado pela Editora Trevo, em maio de 2020. Além disso, tem poemas publicados nas revistas Ruído Manifesto e Mallarmargens. 
Samuel Beckett é um escritor irlandês que nasceu em Dublin, capital da atual República da Irlanda, em 1906 e morreu em Paris, França, em 1989. Beckett, durante a Segunda Guerra Mundial, atuou na Resistência Francesa e pôde ver de perto a destruição causada pela guerra. Apesar de muito discutida a influência da Segunda Guerra no teatro e na prosa de Beckett, pouco é falado acerca do impacto causado em sua poesia. Como pontua Rónán McDonald (2006, p. 4, minha tradução'), a poesia de Beckett "é uma parte lamentavelmente negligenciada da sua obra".

"Dieppe", "Saint-Lô" e "Antipepsis" são poemas, inéditos no português do Brasil, que Beckett compôs possivelmente no período entre os anos de 1937 e 1945 enquanto resistia ao nazismo na França, assumindo uma postura visivelmente antifascista (BOA, Stephen, 1997, p. 7). Dito isto, apresento-os na ordem em que foram publicados, seguidos das minhas traduções, conforme a edição crítica The Collected Poems of Samuel Beckett (2012), organizada por Seán Lawlor e John Pilling. Esta edição serviu como texto-base para as traduções, comentadas a seguir.

2 Salvo se indicado, todas as traduções nesse trabalho são minhas. 


\section{Dieppe}

again the last ebb

the dead shingle

the turning then the steps

towards the lights of old

\section{Saint-Lô}

Vire will wind in other shadows unborn through the bright ways tremble and the old mind ghost-forsaken sink into its havoc

\section{Antipepsis}

And the number was uneven

In the green of holy Stephen

Where before the ass the cart

Was harnessed for a foreign part.

In this should not be seen the sign

Of hasard, no, but of design,

For of the two, by common consent,

The cart was the more intelligent.

Whose exceptionally pia

Mater hatched this grand idea

Is not known. He or she,

Smiling, unmolested, free,

By this one act the mind become

A providential vacuum,

Continues to stroll amok,

To eat, drink, piss, shit, fart and fuck,

Assuming that the fucking season

Did not expire with that of reason.

Now through the city spreads apace

The cry: A thought has taken place!

A human thought! Ochone! Ochone!

Purissima Virgo! We're undone!

Bitched, buggered and bewilderèd!

Bring forth your dead! Bring forth your dead!

\section{Dieppe}

outra última maré

o seixo morto

a volta então a pé

até a luz remota

\section{Saint-Lô}

Vire vai virar em outras sombras

não-nascidas tremer entre claras vias

e a velha alma esquecida

decair no próprio caos

\section{Antipepsis}

Era o número inconstante

No santo Stephen verdejante

Onde tudo é diferente

Burro atrás, carroça à frente.

Em acordo deu-se esse caso,

Sem hasard, ou seja, acaso,

Porque o burro consciente

Não se julgava inteligente.

Qual foi o pássaro que pia

Mater chocou tal utopia

Não se sabe. Ele ou ela,

Rindo, livre, sem mazela,

Com esse feito fez-se a mente

Um vácuo conveniente,

Ainda caminha enquanto pode,

Come, peida, caga e fode,

Crendo que o acasalamento

Sobreviveu ao pensamento.

Pelas ruas não mais escasso

O grito: Uma ideia toma espaço

Ochone! Ochone! Ideia humana!

Purissima Virgo! Que má fama!

Traídos, tristes e tortos!

Tragam seus mortos! Tragam seus mortos!

A fim de facilitar a leitura durante a análise dos poemas traduzidos, organizei-os em tabelas ao lado dos originais e quanto à métrica usei os símbolos $(/),(\backslash)$, $(-),(\mid)$ e (| |) que significam, respectivamente, sílaba acentuada, sílaba acentuada de maneira secundária, sílaba não acentuada, separação entre pés métricos e pausa na leitura (ou fim de verso). 


\section{Traduzindo "Dieppe"}

\begin{tabular}{|c|c|}
\hline $\begin{array}{l}\text { Dieppe } \\
-/|-||| \mid \\
\text { again the last ebb } \\
-/|/-| \mid \\
\text { the dead shingle } \\
-/|--|-/|| \\
\text { the turning then the steps } \\
/ /-\quad /|-/| \mid \\
\text { towards the lights of old }\end{array}$ & $\begin{array}{l}\text { Dieppe } \\
/-|/--|-/|| \\
\text { outra última maré } \\
-/|-/-| \mid \\
\text { o seixo morto } \\
-/|-/|-/|| \\
\text { a volta então a pé } \\
-/|-/|-/-|| \\
\text { até a luz remota }\end{array}$ \\
\hline
\end{tabular}

Primeiro gostaria de adentrar no plano do conteúdo; Dieppe é uma comuna francesa na região da Normandia, por onde, em 1939, os nazistas invadiram a França. Dieppe tem litoral no Canal da Mancha, o que pode ter sido referenciado no primeiro verso do poema "again the last ebb". Publicado no jornal The Irish Times em 1945 sob o título “DIEPPE 193?”, é impreciso quando nos anos 1930 ele foi composto. Contudo, orientado pelo comentário de Seán Lawlor e John Pilling (2012, p. 384), creio que o poema tenha sido composto entre 1937 e 1939 , nos contextos de ascensão do nazifascismo na Europa ou da Queda da França. O poema original tem um tom melancólico e pessimista, tratando o tempo com a metáfora das ondas do mar, que avançam somente para retornar em um ciclo infindável, semelhante ao tempo monótono, tedioso e estático de Waiting for Godot (1955). Palavras como "last", "dead" e "old" reforçam a passagem iminente do tempo, no entanto, as palavras "again" e "turning” fazem com que a progressão do tempo ocorra de maneira não linear, mas cíclica, repetida. Dessa forma, "Dieppe" apresenta um imbricado paradoxo temporal. Além disso, palavras polissêmicas contribuem para o efeito de imprecisão daquilo descrito pelo poema original: "shingle" pode ser traduzido tanto como "seixo" quanto como "telha", enquanto que "steps" pode ser traduzido tanto como "passos/pegadas" quanto como "degraus". Assim, sobreposta à imagem de uma praia de cascalhos com um caminho até as "velhas luzes" (da cidade, possivelmente) ${ }^{3}$, está a imagem da "telha morta" e dos degraus que remetem a ruínas de construção. A imprecisão dota o poema de uma sensação de amorfia, e é justamente essa falta de forma

3 Apesar do adjetivo "old" não se referir a nenhum substantivo em "towards the lights of old", comportando-se ele próprio como substantivo, há a versão em francês do poema, escrita pelo próprio autor, no qual se lê, traduzido literalmente, "em direção às luzes antigas". 
que, conforme Olga Kempinska (2016, p. 194), faz crescer a experiência do tédio na obra de Beckett:

\begin{abstract}
$\mathrm{Na}$ leitura de Beckett, mesmo aquela muito atenta, algo parece relutar em configurar-se, algo não toma forma, insistindo em demorar-se numa monstruosidade amorfa, tal uma neblina cinzenta, uma poeira ou uma lama, que é, aliás, uma das imagens mais recorrentes na poética beckettiana. Comparável a um amálgama sem articulação, o tédio nada tem a ver com os monstros confeccionados da hibridação animal, vegetal e humana. Ao contrário daquela exorbitância de formas, na experiência do tédio trata-se, antes, da impressão do contato com uma estranha substância, quase inexistente e, contudo, capaz de dissolver as formas mais horrendas.
\end{abstract}

No plano rítmico, o poema original apresenta quatro versos de metro irregular, contudo, repete-se com alguma frequência o pé jâmbico (presente em todos os versos). Assim, tem-se, nesta ordem: um jambo e um báquio no primeiro verso; um jambo e um troqueu no segundo; dois jambos intercalados por um pirríquio no terceiro e o quarto verso é composto todo por jambos, com a omissão de uma sílaba no primeiro pé métrico (headless line). A recorrência da alternância entre sílabas tônicas e átonas, a meu ver, expressa no plano rítmico algo expresso também no plano do conteúdo; com a possibilidade de os pés jâmbicos representarem o ritmo das ondas do mar que, no segundo verso, encontram a resistência do pé complementar ao jambo (o troqueu), numa espécie de refluxo do mar, para então ser restabelecido o ritmo jâmbico.

Desta maneira, preocupei-me em recriar essa relação entre sentido e ritmo na minha tradução. Semanticamente, preferi palavras que em português fossem capazes de dar o tom ambíguo e paradoxal do poema em inglês sem perder de vista o número de sílabas poéticas dos versos do poema original (levando em consideração a contagem de sílabas métricas em língua portuguesa que exclui as sílabas átonas após a tônica da última palavra do verso) porque creio que seja imprescindível recriar os efeitos sonoros atrelados à métrica, criando um tom similar ao do original através da acentuação silábica. Além disso, adaptei a recorrência do som $[\varepsilon]$ de "ebb", "dead" e "step" pela recorrência do mesmo som em "maré", "pé" e "até". Assim, as palavras que denotam a passagem do tempo "last", "dead" e "old" foram traduzidas por "última", "morto" e "remota", respectivamente. Enquanto as palavras que impõem a repetição do tempo "again" e "turning" foram traduzidas por "outra" e "volta", respectivamente. Deve-se notar que preferi traduzir "again" por "outra" tendo em vista o número de sílabas a mais que uma tradução mais literal para o termo em português "novamente" traria, prejudicando 
o ritmo do poema. Desta maneira, creio que o verso "outra última maré" tem em si o sentido paradoxal pela associação absurda de palavras que juntas deveriam anular seus sentidos mutuamente, uma vez que se espera que depois da última maré não venha existir outra.

Ainda quanto ao ritmo, quis recriar a predominância do pé jâmbico, sendo todos os versos da minha tradução, com exceção do primeiro, iniciados por um jambo. O que ocorreu, por assim dizer, foi que precisei pôr o "refluxo sonoro" do mar no primeiro verso. Contudo, como este é o verso que trata da "maré vazante" a que se refere a palavra em inglês "ebb", não encarei como perda, mas sim como uma adaptação feliz e reforço da relação entre ritmo e sentido. Além disso, fiquei contente com tal reforço porque "ebb" não encontra em português um correspondente formado por uma única palavra, sendo necessário o adjetivo "vazante" para qualificar a maré; assim, vejo o reforço do sentido através do ritmo como um ganho considerável tendo em vista as especificidades de cada sistema linguístico. Em termos da métrica corrente em língua portuguesa tem-se então: um verso de sete sílabas com acentos nas posições (1), (3) e (7) no primeiro verso; um verso de quatro sílabas com acentos nas posições (2) e (4) no segundo; um verso de seis sílabas com acentos nas posições (2), (4) e (6) no terceiro e um verso de seis sílabas com acentos nas posições (2), (4) e (6) no quarto.

\section{Traduzindo "Saint-Lô"}

\begin{tabular}{|c|c|}
\hline Saint-Lô & Saint-Lô \\
\hline$/ \begin{array}{llllllll} & -1 & / & -1 & / & -1 & / & -11\end{array}$ & $1 \quad 1|-1|-1 \mid-1$ \\
\hline $\begin{array}{l}\text { Vire will wind in other shadows } \\
-/|--| /-|/-| \mid \\
\text { unborn through the bright ways tremble }\end{array}$ & $\begin{array}{l}\text { Vire vai virar em outras sombras } \\
/ \quad-|/-|-/|/-| /-|/-| \mid \\
\text { não-nascidas tremer entre claras vias }\end{array}$ \\
\hline $\begin{array}{l}-\quad|/-| /-|/-| \mid \\
\text { and the old mind ghost-forsaken }\end{array}$ & $\begin{array}{l}-/|/-|-/-|| \\
\text { e a velha alma esquecida }\end{array}$ \\
\hline $\begin{array}{l}/-|--| /-|| \\
\text { sink into its havoc }\end{array}$ & $\begin{array}{l}-\quad /|-/|-/|| \\
\text { decair no próprio caos }\end{array}$ \\
\hline
\end{tabular}

Em relação ao segundo poema, "Saint-Lô", como feito com "Dieppe", adentro no plano do conteúdo para depois chegar ao plano rítmico do texto. Saint-Lô também é uma comuna francesa situada na região da Normandia. Não por acaso, foi palco de confrontos entre aliados e nazistas e alvo de bombardeios em embates tanto de invasão quanto de reconquista. Vire, nome que pode soar estranho em uma primeira leitura, é um rio que passa pela comuna e levei em 
consideração a pronúncia francesa [vir] na contagem de sílabas tanto em inglês quanto em português, porque, apesar de parecer um dissílabo quando lido em português do Brasil, trata-se de um monossílabo.

O tom de "Saint-Lô" parece dar continuidade ao de "Dieppe": tem-se novamente o tema da água, no primeiro representado pelo mar, aqui pelo Rio Vire, como símbolo resistente à violência da guerra. Apesar da destruição, as ondas do mar continuam avançando sobre a praia em "Dieppe", e aqui o Vire segue seu curso sem interferências, como reforça Pilling (1997, p. 194):

sua ideia inicial de continuação e continuidade ('Vire will wind...') retoma um motivo da fala no rádio4: 'o hospital de cabanas de madeira em seus jardins entre o Vire e as ruas de Bayeux continuará a executar suas funções, e suas curas.

A sensação de claustrofobia na escrita beckettiana (LANGLOIS, 2017, p. 18), evidenciada nesses poemas pela impossibilidade do próprio tempo de escapar das ruínas de Dieppe e Saint-Lô, acrescida do elemento água faz ecoar a palavra-valise "sepúltero" (trad. de Caetano e Rogério W. Galindo para "womb-tomb”) de Ossos de Eco (2015): o ponto de partida, o útero, e o ponto final, a sepultura, fundem-se. E a humanidade, o mundo, é ao mesmo tempo embrião e cadáver. "Saint-Lô" e "Dieppe" mostram o poder monstruoso da guerra de suspender o tempo natural e de pôr os sujeitos humanos em um estado não de morte, mas de anti-vida; de obliteração da existência.

Portanto, o que se reduz a "sombras não-nascidas" aqui são as construções transformadas em ruínas, incapazes de erguerem-se verticalmente do solo, deixando à mostra os "bright ways" talhados na cidade pela guerra. A expressão "old mind" possivelmente se refere à própria Saint-Lô que se encontra abandonada até pelos fantasmas, uma vez que, de tão arrasada, a cidade não pode ser habitada nem pelos espíritos daqueles que morreram ali e, assim, afunda em caos como o Rio Vire. "Saint-Lô" apresenta uma sintaxe complexa: o verbo auxiliar "will" pode estar regendo os verbos "tremble" e "sink" (LAWLOR; PILLING, 2012, p. 390), dessa maneira o poema poderia ser lido, em ordem direta: "Vire vai virar em outras sombras não-nascidas, [Vire vai] tremer entre claras vias e a velha alma esquecida, [Vire vai] decair no próprio caos".

4 The Capital of Ruins. 
Em questão de ritmo, o poema original é composto por quatro versos os quais os três primeiros têm quatro pés métricos enquanto o último três. Nestes quatro versos predomina o uso do pé trocaico, presente em todos os versos. Assim, tem-se, nesta ordem: quatro troqueus no primeiro verso; um jambo, um pirríquio e dois troqueus no segundo; um pirríquio, e três troqueus no terceiro e dois troqueus intercalados por um pirríquio no quarto. A recorrência do pé trocaico em "Saint-Lô" ecoa o uso de seu pé complementar (o jambo) em "Dieppe" e de forma semelhante expressa no plano rítmico o que é expresso no plano do conteúdo do poema, já que o único verso uniforme do poema é aquele que trata do curso inalterado do rio Vire, enquanto os versos que tratam das ruínas da cidade apresentam pouca ou nenhuma uniformidade.

O jogo com palavras antitéticas presente no poema anterior também figura em "Saint-Lô" na oposição entre "shadows" no primeiro verso e "bright" no segundo, além do eco da fluidez do rio Vire no último verso através do verbo "sink". No primeiro verso, adaptei as aliterações de [w] em "will" e "wind" por aliterações em [v] em "Vire", "vai" e "virar", ganhando assim mais uma repetição do som. No segundo verso, traduzi a palavra "bright" por "claras", recriando a relação de antítese com "sombras" ("shadows" no original). No terceiro verso, preferi traduzir "mind" por "alma" em vez de "mente" em prol da economia de sílabas gerada pela elisão da vogal final de "velha" com a inicial de "alma", e da final de "alma" com a inicial de "esquecida". Ainda no terceiro verso, não recriei um trocadilho correspondente a "ghost-forsaken", traduzindo-o pelo termo mais geral "esquecida"; apesar disso, não querendo de todo abrir mão de um termo linguisticamente marcado (BRITTO, 2012, p. 67), reproduzi no verso anterior uma construção marcada em português "não-nascidas" (com hífen para fazer referência ao "ghost-forsaken") que traduz "unborn". No quarto e último verso, não reproduzi a referência à água contida em "sink", mas reproduzi as aliterações em $[\mathrm{k}]$ presentes tanto em "sink" quanto em "havoc" por aliterações de mesma natureza em "decair" e "caos", preferi as aliterações em vez do sentido de "sink" porque o som da oclusiva $[\mathrm{k}]$ tende a ser associado com a ideia de dureza (FALEIROS, 2012, p. 149), que remeteria às ruínas.

Em minha tradução não verti um ritmo regular no verso que trata do curso do rio Vire, deslocando tal regularidade para o segundo verso do poema traduzido, que possui apenas um pé que não seja trocaico. Desta maneira, tem-se no poema traduzido: um verso de oito sílabas com acentos nas posições (1), (2), (4), (6) e (8) no primeiro verso; um verso de onze sílabas com acentos nas posições (1), (3), (6), (7), (9) e (11) no segundo; um verso de seis sílabas com 
acentos nas posições (2), (3) e (6) no terceiro e um verso de sete sílabas com acentos nas posições (3), (5) e (7).

\section{Traduzindo "Antipepsis"}

"Antipepsis", o último poema traduzido, segundo Seán Lawlor e John Pilling (2012, p. 391), foi composto em octossílabos por esse ser um metro de sátira encontrado em textos como "Hudibras" de Samuel Butler e "The Holy Office" de James Joyce, os quais teriam inspirado Beckett. Privilegiei tanto a recriação das rimas e dos jogos de palavras quanto a recriação da métrica. Portanto, sublinhei, tanto no original quanto em minha tradução, os versos de oito sílabas. 


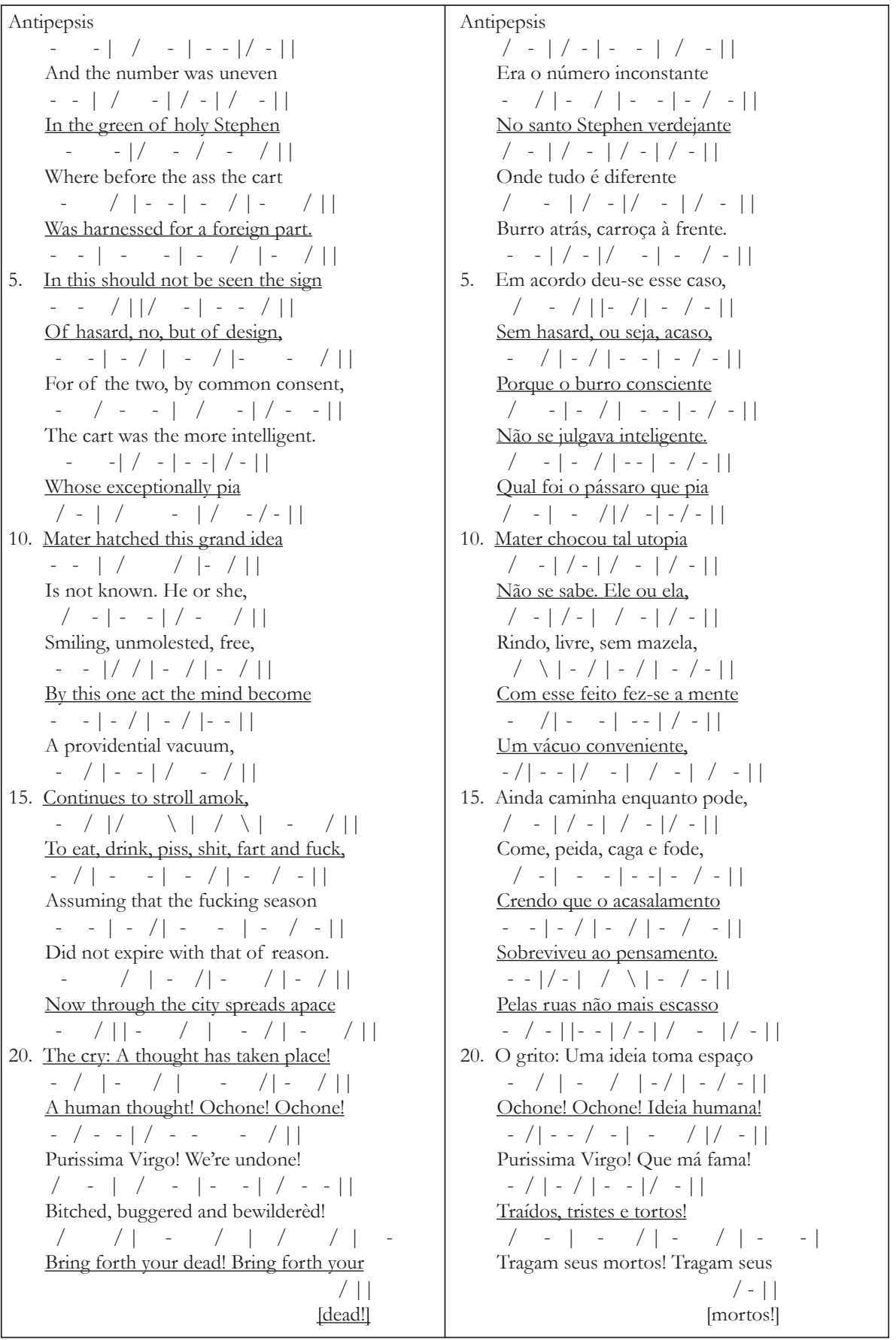


Os dois primeiros versos do poema são responsáveis por criar uma relação direta entre Irlanda e França, uma vez que "in the green of holy Stephen" faz alusão ao parque St. Stephen's Green, em Dublin, nos arredores de onde ficava a sede do hospital Irish Red Cross que atuava na França, em Saint-Lô. Dessa maneira o poema trabalha constantemente com pares que vão se manifestar no texto através também das rimas emparelhadas. Além disso, há no decorrer de todo o poema a dicotomia entre corpo e mente textualizada através das constantes referências a processos/qualidades mentais como em "design", "intelligent", "idea", "mind" e "thought" em oposição ao corpo destituído de seu aspecto psíquico, restando apenas a fisiologia, como no verso "To eat, drink, piss, shit, fart and fuck". Tal dicotomia recupera a relação antitética entre algumas das palavras empregadas tanto em "Dieppe" quanto em "Saint-Lô" e remete ao próprio título do poema que contém o prefixo grego "anti" acrescido da palavra de mesma origem "pepsis" ("digestão"); o que lembra ainda a palavra inglesa para "antissepsia", "antisepsis" (LAWLOR; PILLING, 2012, p. 392), portanto, uma dupla antítese: "Antipepsis" como contrário de digestão e como contrário de antissepsia - assim, o título do poema opera com a sensação de repulsa frente à insalubridade. No terceiro verso, há a reelaboração do dito popular "to put the car before the horse" (que encontra em português o correspondente "pôr a carroça na frente dos bois"). Nesse verso o cavalo ("horse") é transformado em um burro ("ass") que é o menos inteligente em comparação à carroça ("cart") que deveria puxar, tanto quanto é menos nobre em relação ao cavalo que ocupa seu lugar no dito tradicional. Assim, "em acordo deu-se esse caso", quem os conduz é a carroça já que o burro é inapto para ocupar essa posição. Segundo Seán Lawlor e John Pilling (2012, p. 392-393), o alvo da sátira de "Antipepsis" poderia ser a equipe do hospital Irish Red Cross que, apesar de estar em cenário de guerra e destruição, mantinha comportamentos considerados lascivos aos olhos de Beckett, como, por exemplo, viagens de ambulância a um bordel nas ruínas de Saint-Lô. Se assim for, é possível enxergar a "carroça" do poema também como uma referência aos "body transfer carts" enquanto o "burro" pode ser representação da equipe que os conduz: assim, a imagem de uma maca para transporte de cadáveres tendo mais consciência que um ser-humano é construída. Considerando que o cenário de "Antipepsis" é a própria Saint-Lô arruinada a ponto de estar "ghost-forsaken" e que o burro é privado de todas as suas qualidades psíquicas, restando-lhe apenas suas funções corporais básicas, é difícil discernir se os mortos evocados pelo último verso do poema seriam as vítimas dos bombardeios, a equipe médica estupefata pela guerra ou ambos, sem diferenciação, vivendo o estado de obliteração da existência, o estado de anti-vida que mencionei anteriormente. 
Como propus trabalhar o poema tendo em mente sua relação de duplicidade, creio que a sátira à equipe médica encontra seu par em uma sátira ao governo irlandês pela censura de More Pricks Than Kicks (1934), o que também teria motivado Beckett a escrever "Antipepsis", além disso, creio ser possível tomar um outro ponto de vista enxergando a sátira política em um contexto mais amplo. Dessa maneira, em um cenário de ascensão de regimes totalitários, os ditadores (as carroças) fazem o povo de determinado país (os burros) crerem que os primeiros são mais bem preparados para conduzir a nação, apesar de ser bem sabido que carroça alguma é preparada para guiar um equino.

Traduzi o poema tendo em mente esses aspectos gerais. Recriei as rimas emparelhadas, os versos de oito sílabas, a dicotomia temática de corpo/mente e as marcas de estrangeirismo como o uso do francês ("hasard"), do latim ("Pia Mater" e "Purissima Virgo") e do irlandês ("Ochone! Ochone!") além de ter preferido não traduzir para o português o nome "Stephen".

Tomei essa última decisão tendo em mente o que Antoine Berman (2013, p. 34-35) caracteriza como "tradução ética", que respeita as marcas culturais do original na tradução, livrando-as do filtro etnocêntrico. Nos terceiro e quarto versos do poema original, "ass" e "harnessed" apresentam aliteração em [s], não pude reproduzir uma aliteração da mesma natureza, por isso adaptei por uma aliteração em [r] entre "burro" e "carroça". No quinto verso do poema original, "this", "seen" e "sign" apresentam aliteração em [s], pude reproduzir em minha tradução uma aliteração de mesma natureza com "deu-se" e "esse". No sétimo verso do poema original, "common" e "consent" apresentam aliteração em [k], pude reproduzir uma aliteração da mesma natureza com "porque" e "consciente".

A partir do décimo sexto verso do poema original "To eat, drink, piss, shit, fart and fuck", precisei fazer uma série de cortes semânticos mais significativos em minha tradução. Esse mesmo verso, teve seu número de verbos reduzido de seis no original para quatro em minha tradução. Isso se deu porque todos os verbos do original são monossílabos, que ocupam, portanto, menos espaço em questão de métrica, enquanto os verbos da minha tradução são dissílabos. Com isso não reproduzi os pares "to eat/to shit" e "to drink/to piss" do original, reproduzi apenas os verbos com sentido mais significativo para compor o tom geral de comicidade e de dicotomia entre processos psíquicos e fisiológicos presente no poema original de Beckett, tem-se em minha tradução, portanto, o verso "Come, peida, caga e fode". No vigésimo primeiro verso do original "A human thought! Ochone! Ochone!", eu trouxe as interjeições irlandesas de lamento para o início do verso. Fiz isso para obter a rima entre "humana" e "fama", apesar de estar 
distanciando-me semanticamente de "We're undone" ao traduzir por "Que má fama". No vigésimo terceiro verso, distanciei-me ainda mais semanticamente do original ao traduzir "Bitched, buggered and bewilderèd" por "Traídos, tristes e tortos". Contudo, adaptei as aliterações em [b] do poema original por aliterações em [t] em minha tradução, além de ter conseguido a rima entre "tortos" e "mortos".

Assim, como diz Paz (2009, p. 23), creio que o bom tradutor "[n]ão se afasta do poema senão para segui-lo mais perto”. Dessa maneira, afastei-me do conteúdo semântico do poema para privilegiar justamente aquilo que diferencia a linguagem poética do uso corrente da linguagem. A tradução de poesia deve privilegiar aquilo que caracteriza um texto como poema, sua relação entre forma e conteúdo. Traduzir apenas o significado ou apenas os aspectos formais seria insuficiente; é preferível, portanto, traduzir dentro de um mesmo universo semântico sem abrir mão dos aspectos formais como rimas, aliterações e assonâncias. Pois, "se é o poema todo que constitui a unidade de significância, também será o poema todo a unidade de tradução poética” (LARANJEIRA. 2003, p. 84). Paulo Rónai (1981, p. 146-147) também enxerga o poema em sua totalidade como unidade de tradução poética e comenta um caso da tradução de um poema com dezesseis versos:

Um tradutor húngaro, László Kálnoky pergunta a si mesmo a que processo obedecer ao verter um poema de dezesseis versos em que quatro rimas se alternam de maneira mais ou menos regular. Resolver os versos um por um não adianta, pois a melhor solução pode ser anulada pela inexistência de rima no segundo, terceiro ou quarto verso correspondente. Em caso tão difícil o tradutor só alcança êxito se consegue conceber aquela única sentença de dezesseis linhas como uma unidade indivisível e vertê-la com um método simultâneo, isto é, enquanto resolve um dos versos, não perder de vista um minuto sequer os quinze outros.

Portanto, o que fiz ao traduzir "Dieppe", "Saint-Lô" e "Antipepsis" foi encarar os poemas como porções indivisíveis de texto que estabelecem relações umas com as outras através da recorrência do estilo, do tema, do tom, de palavras e de figuras de linguagem. "Dieppe" introduz imagens que serão retomadas por "Saint-Lô" a fim de serem exploradas mais longamente em "Antipepsis". Dessa maneira, os poemas deveriam, em princípio, ser apresentados em conjunto para que fique evidente o diálogo que se estabelece entre eles. Dito isso, as porções indivisíveis de texto que são esses poemas de Beckett combinam-se para formar uma trindade consubstancial: três poemas distintos que partilham a mesma "substância" ou "natureza". Não por acaso aqui o discurso poético remete ao discurso religioso, como aponta Paz (2017, p. 22-23): 
[a] sociedade não pode perdoar a poesia, pela própria natureza desta: ela lhe parece sacrílega. E mesmo que a poesia se disfarce, aceite comungar no altar comum e prontamente justificar sua embriaguez com todo tipo de razões, a consciência social a reprovará sempre como um extravio e uma loucura perigosa. [...] Nessa comunhão buscada pelo poeta, ele descobre a força secreta do mundo, essa força que a religião pretende canalizar e utilizar, e até apagar, por meio da burocracia eclesiástica. E o poeta não apenas a descobre e funde-se com ela; diferentemente do místico, ele a revela em toda a sua aterradora e violenta nudez ao resto dos homens, pulsando na sua palavra, viva nesse estranho mecanismo de encantamento que é o poema.

Dessa maneira, ainda conforme Paz (Idem, p. 35), "a poesia continua sendo uma forma capaz de revelar ao homem seus sonhos e convidá-lo a vivê-los em pleno dia". No caso dos "poemas de guerra" de Beckett, a poesia convida o homem a reviver não sonhos, mas sim pesadelos, a fim de que através da rememoração não sejam cometidos os mesmos horrores mais uma vez. Traduzo esses poemas de Beckett tendo em mente "a noção de que a operação tradutora está ligada necessariamente à construção de uma tradição” (CAMPOS, 2013, p. 79), sendo entendido por "tradição" a apropriação do passado através de uma ótica do presente (Idem, p. 83). Traduzir esses "poemas de guerra" então é, simultaneamente, olhar para o passado e para o presente, percebendo as similaridades entre ambos e traçando paralelos.

\section{Referências bibliográficas}

BECKETT, Samuel. Ossos de Eco. Trad. Caetano W. Galindo e Rogério W. Galindo. São Paulo: Editora Globo, 2015.

BECKETT, Samuel. The Collected Poems of Samuel Beckett. Seán Lawlor e John Pilling (Ed.). Nova York: Grove Press, 2012.

BERMAN, Antoine. A tradução e a letra ou o albergue do longínquo. Trad. Marie-Hélène C. Torres, Mauri Furlan, Andreia Guerini. Florianópolis: PGET/UFSC, 2013.

BOA, Stephen. Reading Self-Resistance in the Works of Samuel Becket. Montreal: Universite de Montréal, 1997. Disponível em: collectionscanada.gc.ca/obj/s4/f2/dsk3/ftp04/nq43468. pdf Acesso em 25 fev. 2021.

BRITTOO, Paulo Henriques. A tradução literária. Rio de Janeiro: Civilização Brasileira. 2012.

CAMPOS, Haroldo de. Da tradução como criação e como crítica. In: NÓBREGA, Thelma Médici; TÁPIA, Marcelo (Org.). Haroldo de Campos - Transcriação. São Paulo: Editora Perspectiva, 2013.

FALEIROS, Álvaro. Traduzir o poema. São Paulo: Ateliê Editorial, 2012. 
KEMPINSKA, Olga. Tédio na leitura de Beckett. In: outra travessia, $\mathrm{n}^{\circ} 22$, segundo semestre de 2016, p. 193-208. Florianópolis, 2016. Disponível em: https://periodicos.ufsc.br/index. php/Outra/article/view/2176-8552.2016n22p193 Acesso em 25 fev. 2021.

LANGLOIS, Christopher. Samuel Beckett and the Terror of Literature. Reino Unido: Edinburgh University Press, 2017.

LARANJEIRA, Mário. Poética da Tradução: do Sentido à Significância. $2^{\circ}$ edição. São Paulo: Edusp, 2003.

MCDONALD, Rónán. The Cambridge Introduction to Samuel Beckett. Cambridge: Cambridge University Press, 2006.

PAZ, Octávio. Poesia de solidão e poesia de comunhão. In: JARDIM, Eduardo (Org. e trad.). A busca do presente e outros ensaios. Rio de Janeiro: Bazar do Tempo, 2017.

PAZ, Octávio. Tradução, literatura e literalidade. Trad. Doralice Alvez de Queiroz. Viva Voz. Belo Horizonte: FALE/UFMG, 2009.

PILLING, John. Beckett Before Godot. Cambridge: Cambridge University Press, 1997.

RÓNAI, Paulo. A Tradução Vivida. $2^{\mathrm{a}}$ ed. Rio de Janeiro: Editora Nova Fronteira, 1981. 